If anything could demonstrate the propensity for fly-catching $\mid$ in the most marked degree. You will see that a moth has been known to exist in this class of plants, surely this specimen does entangled by the hairs of one of the leaves, which leaf has curved

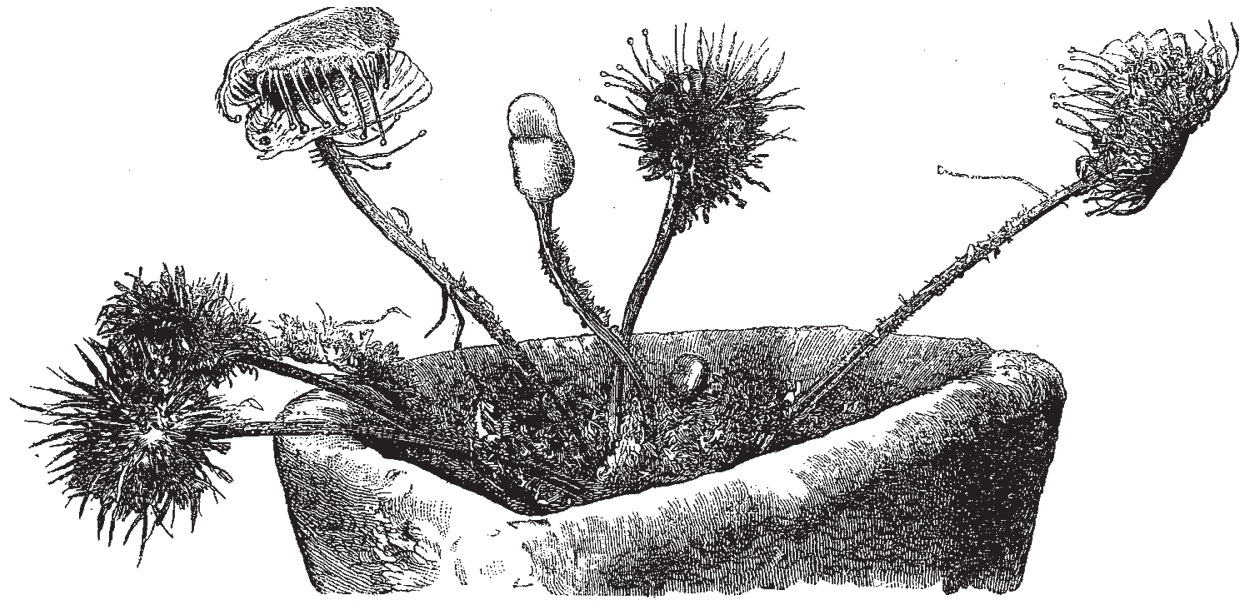

itself right over the moth in the most determined fashion. There is every appearance of a struggle having taken place which ended in the defeat and destruction of the moth。
This specimen is, I should imagine, a very typical one, and as such I have sent a copy to Mr. Darwin. WRIGHT WILSON Birmingham

\section{The Radiant Centre of the Perseids}

From twenty meteors, mostly with streaks, I deduced the radiant point at R.A. $40^{\circ}$, Dec. $56^{\circ} \mathrm{N}$, August 3-7. On A ugust Io I saw a large number (fifty-seven per hour) of Perseżds, many of them with short tracks near the focus, and almost inva. riably with streaks, from $43^{\circ}+58^{\circ}$. On August I2 I observed quite an outburst of precisely similar meteors from a sharplydefined centre at $50^{\circ}+55^{\circ}$, and registered fourteen of them, but many others were noted between $12 \mathrm{~h}$, and $\mathrm{J} 4 \mathrm{~h}$. On the $16 \mathrm{th}$, between the same hours, I saw five paths close to a radiant at $60^{\circ}+59^{\circ}$. These had streaks and apparently exhibited the same features of motion, colour, \&c., as those recorded on the few preceding nights. Can these four positions represent one and the same system of Perseidds with an apparent displacement of the radiant centre on the several nights of observation? The places may be regarded as accurate for the dates, and though quite possibly they are separate showers, it is at least singular they became so well marked one on each night. If the positions include the same system then the focus of divergence appears to have shifted from $40^{\circ}+58^{\circ}$ on the 3 rd- 7 th to $60^{\circ}+59^{\circ}$ on the $16 t h$, so that while the declination remained nearly the same the R.A. had advanced twenty degrees, which in D. $59^{\circ} \mathrm{N}$. is equivalent to ten linear degrees of space.

It is a capital plan while observing and mapping meteor tracks to hold a perfectly straight rod in the hand, and directly a meteor is seen, to project the rod upon its apparent path, carrying the eye back in the same line of motion and noting the exact point with reference to stars upon which it converges. In the case of slow meteors or meteors with streaks, this is a very accurate method and especially to be recommended in regard to paths presumably a long way from the radiant. Eye-estimates are necessarily less exact, for while the position of the track is being noted the more important feature of direction is inaccurately remembered.

August $\mathbf{r} 7$

\section{Fish Commensals of Medusæ}

IN the numbers of NATURE for July I9 and 26 (pp. 227, 248) are communications respecting fish-sheltering Medusæ. The Trochurus in Europe appears to be a commensal of the Acaleph as well as the Pollochizus. In the eastern waters of the United States, however, so far as I am aware, the Stromatoid fish Poronotus similis (Stromateus similis of some authors) seems to be the most common, if not the only associate, of several acalephs, viz., Dactylometra quinquecirra, Zygodactylon gran. landica, and Cyarea arctica. Under the umbrellas of these species small Poronoti are to be found in the late summer swimming, sometimes even to the number of twenty or more, but generally much few r. Mr. Alexander Agassiz, in his "Sea-side Studies," mentions the occurrence of an undetermined "Clupeoid" fish, but no oiher, under the umbrella of Dactylometra quinquecirra; the identification is probably erroneous. At least my own observations were made in the same region and at the same time of the year as Mr. Agassiz's, and only the Poronotus was seen. More detailed information respecting this association may be found recorded by Prof. Verrill in the "United States Commission of Fish and Fisheries" reports, Part I, pp. 449-450, 1873 .

Smithsonian Institution, Washington, August 6 THEO. GILI

\section{Science in Spain}

I THINK it may interest the readers of your journal to have some slight idea of the state of natural sciences in Spain. Science is universal, and the efforts made by a nation which has been separated by centuries of intolerance and indifference from the movement and scientific life of other countries, cannot fail to be looked upon with indulgent eyes by those who cultivate science.

Of the three great branches into which we may divide natural science-physics, chemistry, and natural history, the first is in a most backward state in Spain. In almost all the professorships where this science is taught, the instruction given is so out of date, that no mention is made of the modern theory of the correlation of forces or thermo-dynamics, and the text-books used are French works, now quite obsolete. In every one of our upper schoolsInstitutos de 2 da Ensiñanza-there is a professor who teaches physics and chemistry conjointly, who is instructed to go through a course of these sciences, which are reduced by this means to their lowest possible expression. In our universities, there exist classes in which an amplification of physics is taught ; this study is part of those required for the preparatory exercises for the faculty of medicine. This course, if we take into consideration the knowledge brought by the pupils who attend it, is more an explanation of what they ought to have learnt than anything else. At the Madrid University alone, there is a class of "imponderable fiuids ; " the name in itself suggests an idea quite out of date at the present day. At the same university there is also a class of mathematical physics, but it does not form part of the studies required to receive a doctor's degree in the physico-chemical sciences, and is only includea in the mathematical sciences. This is unfortunately all the official instruction on the subject which is given in Spain. Almost all the professors follow the theories which were generally admitted before the discoveries of Grove, Mayer, Rankine, Clausius, Tyndall, and Helmholtz.

During the Republican Government in Spain, it was decreed to reorganise these studies in a manner more in accordance with modern ideas, but the short rule of this reforming government prevented this plan from being carried out, or conquering the 